Endocrinol. Japon. 1963, 10 (1), 60 68

\title{
A NEW ASSAY METHOD FOR THYROTROPIG HORMONE BASED ON THE IODINATION OF THYROGLOBULIN IN HOG THYROID SLICES*
}

\author{
YOICHI KONDO AND NOBUO UI \\ Department of Physical Chemistry, Institute of Endocrinology, \\ Gunma University, Maebashi
}

For many years, efforts have been made to devise a satisfactory method for the assay of thyrotropic hormone (TSH). At present a great diversity of methods are available (Turner, 1962), based on the various biological and metabolic effects of TSH, and some of them are reported to be sensitive enough to detect the small amounts of TSH presenting in biological fluids (McKenzie, 1960; Crigler, 1960). Nevertheless, even these improved methods are far from being satisfactory, because of the technical difficulty, variability or tediousness. Most of the assay methods hitherto proposed involve measurements of the effect of TSH upon the series of consecutive reactions occuring in thyroid. The responses are, therefore, liable to be influenced by other factors. Although the exact site of TSH action is not clear at present, it seems desirable that an assay should be designed to measure the effect of TSH as directly as possible.

As reported in the previous papers (Kondo, 1961a and b), TSH was found to enhance the process of the $I^{131}$-transfer from intrathyroidal pool of iodide to thyroglobulin molecules without affecting the total incorporation into the slices, if hog thyroid slices are incubated with $\mathrm{I}^{131}$ only for a short period. It was also observed that this early effect of TSH on $\mathrm{I}^{131}$ incorporation was specific to TSH and the response was a linear function of the logarithm of the dose. Although it is premature to presume that the phenomenon is due to the primary action of TSH, this finding is considered to be valuable for the in vitro assay of TSH.

The purpose of the present paper is to describe the details of this new assay method. This method is not so sensitive, but provides an useful assay method, especially for the partially purified preparations of TSH obtained during the course of purification study, because of its simplicity as well as its reliability.

\section{MATERIALS}

TSH preparations used in this study were U.S.P. Thyrotropin Reference Standard (0.074 U.S.P. U/mg $=0.074$ I.U./mg) and a whale pituitary TSH preparations. The latter was prepared in this laboratory according to a modified Ciereszko's method (Ciereszko, 1945) and its activity was approximately 1 I.U./mg.

All other chemicals were commercial products of reagnet grade and used without further purification.

Received for publication December 18, 1962.

* This work was supported by Grant in Aid for Scientific Research from the Ministry of Education. 


\section{ASSAY PROCEDURE}

The standard assay procedure finally adopted is described below. The same method was used throughout the present study unless other methods were stated in the paper.

\section{Preparation of thyroid slices}

Hog thyroid glands obtained at a slaughter-house are kept on ice until used. The glands are freed from extraneous tissues and fat, and cut into blocks appropriate for slicing. Small slices, $0.5 \sim 0.7 \mathrm{~mm}$ thick and $1 \sim 2 \mathrm{~mm}^{2}$ in area, are prepared with a razor blade. In order to minimize the effects due to the variability of response from gland to gland, 5 to 10 glands of nearly the same weight (ca. $10 \mathrm{~g}$ ) are used at one time and the slices are combined. These mixed slices are then rinsed collectively twice in $200 \mathrm{ml}$ of an ice-cold Krebs-Ringer phosphate buffer, in which the concentration of calcium chloride is $1 / 2$ of the usual concentration, and blotted on filter paper.

\section{Incubation}

Incubation is performed in a $20 \mathrm{ml}$ beaker containing $3 \mathrm{ml}$ of the modified Krebs-Ringer phosphate buffer ( $\mathrm{pH} 6.8$ ), $1.18 \mathrm{~m} \mu M$ of potassium iodide $\left(0.15 \mu \mathrm{gI}\right.$ ), $5 \mu \mathrm{C}$ of $\mathrm{NaI}^{131}$ as a tracer, and the TSH preparation to be tested. The appropriate concentration of TSH for the assay is $5 \sim 10 \mathrm{I} . \mathrm{mU} . / \mathrm{ml}$. Before adding the slices, the beakers containing the medium are placed on a shaking incubator and kept at $37^{\circ} \mathrm{C}$ for about a few minutes. After this, the reaction is started by the addition of $200 \mathrm{mg}$ of thyroid slices, previously weighed with a torsion balance, to each beaker. Incubation is continued in the air for $15 \mathrm{mins}$. at $37^{\circ} \mathrm{C}$. The shaking rate is about 100 strokes per min. In order to achieve accurate results, the same experiments are tried in 2 or 3 beakers prepared for each concentration of TSH and the observed values of responses to TSH are averaged. Usually assay is performed at two or three different concentrations of TSH.

\section{Separation of the reaction products}

At the end of the incubation, the slices in the reaction mixture are separated from the medium on "Saran" net and rinsed twice with $5 \mathrm{ml}$ of the cold Krebs-Ringer phosphate buffer containing $0.5 \%$ of thiourea. Then, the slices are transfered to a Potter-Elvehjem glass homogenizer and thoroughly homogenized with $1 \mathrm{ml}$ of $0.5 \%$ thiourea solution. A portion of the homogenate, usually $0.01 \sim 0.02 \mathrm{ml}$, is applied on a paper strip $(2 \times 40 \mathrm{~cm}$, Toyo Filter Paper No. 50) and developed for $18 \sim 24 \mathrm{hrs}$. using n-buthanol saturated with $2 \mathrm{~N}$-ammonium hydroxide as a solvent.

\section{Determinatian of the percentage $I^{131}$-incorporation into the protein fraction}

After drying of the paper strip, the area around the origin is cut, and then its radioactivity is determined. At the same time, the radioactivity of the rest of the paper strip is counted and the total radioactivity is calculated from the sum of these two values. This total radioactivity is taken as $100 \%$ for the $\mathrm{I}^{131}$-incorporation into slices. Response is expressed as the percentage radioactivity left at the origin.

\section{Preparation of a standard curve}

A standard TSH preparation with known potency (U.S.P. Thyrotropin Reference Standard was used in the present study) is subjected to this assay at various concentrations between 1 and $30 \mathrm{I} . \mathrm{mU} . / \mathrm{m} l$. The percentage radioactivity left at the origin of paper chromatogram is plotted against the logarithm of the concentration of TSH and a standard curve is obtained (Fig. 1). The potency of unknown is estimated by comparing the response curve with the standard curve. As the slope of the response curve varies from experiment to experiment, a new standard curve is required for each assay. 


\section{Dose-response curve}

Under the condition specified, nearly 2 to $5 \%$ of the total $I^{131}$ incorporated into the slices was protein-bound $\mathrm{I}^{131}$. The value increased with the increase in the logarithm of the TSH concentration within the range of 1 I.mU. to 30 or 50 I. $\mathrm{mU} . / \mathrm{ml}$. A typical dose-response curve is shown in Figure 1.

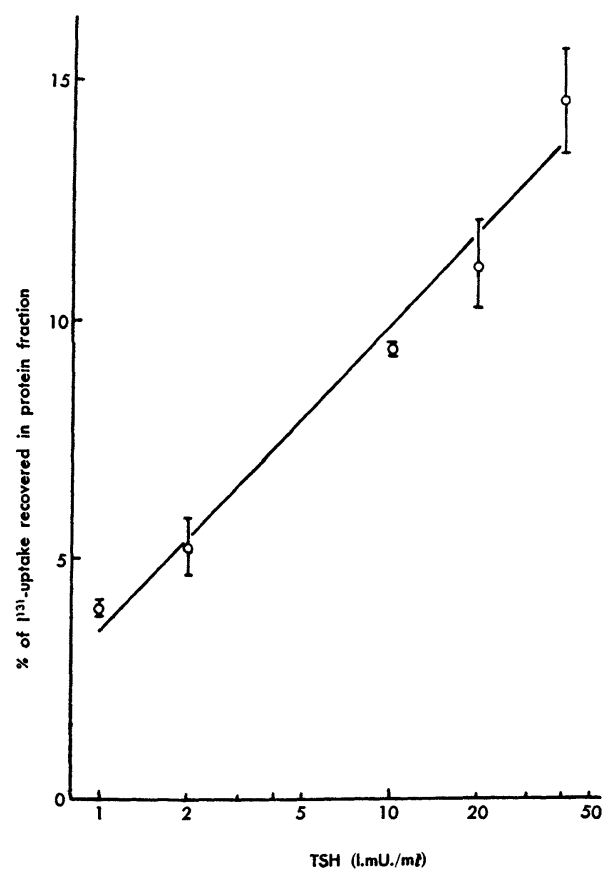

Fig. 1. Dose response curve

0 : mean of 3 beakers

The minimum detectable dose did not differ significantly with experiments. However, the slope of dose-response curve varied considerably with experiments. The index of precision ( $\lambda$ ) was usually between 0.15 and 0.30 . Occasionally the value exceeded this range and the repeated assay was required. However, these cases were only exceptional, being less than $10 \%$ of all experiments.

It was observed that TSH caused neither change in the total $\mathrm{I}^{131}$ uptake by the slices, nor change in the intracellular pool size of iodide during the early incubation period. The only observed change was the effect of TSH upon the labeling of the protein fraction, especially of thyroglobulin. The response was found to be specific. Therefore, the incorporation of $I^{131}$ into protein fraction expressed as percentage of the total incorporation seems to offer a reasonable index of TSH effect upon the rate of intrathyroidal conversion of iodide to thyro- 
globulin-bound iodine.

\section{Effect of the period of incubation}

The stimulation of iodination of thyroglobulin caused by TSH was only observed during the initial incubation period. The effect decreased with time and inhibition occasionally occured after a long incubation. This suggests that the prolonged incubation brings about complication in the iodine metabolism in survival thyroid slices. For this reason, it is preferable that the duration of incubation is as short as possible. In this assay, incubation for 15 mins. was usually employed for the sake of experimental covenience.

\section{Effects of the constituents of the incubation medium}

When the concentration of iodide, added to the incubation medium as substrate, was increased up to $1.0 \mu \mathrm{gI} / \mathrm{ml}$, the $\mathrm{TSH}$ effect disappeared completely (Kondo, 1961b). The concentration, $0.05 \mu \mathrm{g} \mathrm{I} / \mathrm{ml}$, was adopted, in consideration of the results of the previous study.

Attempts were also made to study effects of other constituents in the incubation medium upon the response. When calcium ion was replaced with sodium chloride of the same tonicity, the control rate of the iodination slightly decreased, and the response to TSH disappeared almost completely. The removal of magnesium ion which has the same ionic valency as calcium ion has, did not cause any significant change; rather a slight increase in response was observed. By the substitution of potassium ion with sodium, the control rate increased markedly, while the response to TSH rather decreased. In Table 1 these results are summarized.

Table 1. Effect of cations on the $1^{131}$-incorporation into protein fraction in thyroid slices

\begin{tabular}{|c|c|c|c|}
\hline Incubation medium & \multicolumn{2}{|c|}{$\begin{array}{l}\% \text { of } 1^{131} \text { uptake } \\
\text { recovered in protein fraction* }\end{array}$} & $\begin{array}{c}\text { Mean increase with } \\
\text { TSH }\end{array}$ \\
\hline Complete & 5.5 & 13.2 & +140 \\
\hline Complete, minus $\mathrm{Mg}^{++}$ & 5.2 & 14.0 & +170 \\
\hline Complete, minus $\mathrm{Ca}^{++}$ & 3.2 & 3.6 & +12 \\
\hline Complete, minus $\mathrm{Ca}^{++}$and $\mathrm{Mg}^{++}$ & 2.5 & 4.7 & +88 \\
\hline Complete, minus $\mathrm{K}^{+}$ & 9.1 & 17.5 & +92 \\
\hline
\end{tabular}

* Mean of two beakers

The requirement of calcium ion has been reported also by Bakke and coworkers (Bakke et al., 1957) who showed that calcium ion was indispensable for the effect of TSH on the wet weight of thyroid slices.

In contrast to these findings, calcium or magnesium ion caused marked inhibition in the iodination of thyroglobulin catalyzed by thyroid particulate fraction in cell-free system (Kondo, 1961c; Kondo and Ui, 1961). This might show that the role of calcium ion in the experiments employing slices is not due to its direct action on the iodinating enzyme system but largely due to its effect upon the cell structure. 


\section{Effect of temperature}

In order to determine an optimum temperature, the response to TSH was examined at various temperatures. Using the groups of slices from the same preparation, the experiments at various temperatures were performed with an interval of 30 mins. The results of repeated experiments showed that this way of experiment did not mislead the conclusion described below.

As shown in Figure 2, a maximum response was obtained at $37^{\circ} \mathrm{C}$. At $40^{\circ} \mathrm{C}$, $\mathrm{TSH}$ effect almost vanished, although the rate of iodination was considerably higher than that at $37^{\circ} \mathrm{C}$. At lowering the temperature the response was found to decrease markedly at $34^{\circ} \mathrm{C}$. However, it again increased at $30^{\circ} \mathrm{C}$ and finally vanished at $26^{\circ} \mathrm{C}$. The reason for this curious but reproducible finding remains to be elucidated.
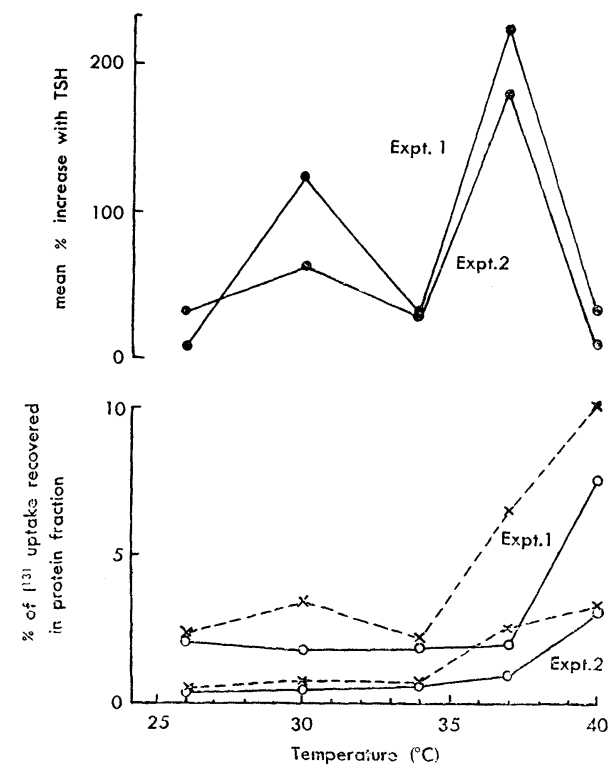

Figi 2. Effect of temperature upon the $\mathrm{I}^{131}$-incorporation into protein fraction in thyroid slices

Incubation time

Expt. 1. : $29 \mathrm{~min}$.

Expt. 2. : $14 \mathrm{~min}$.

-. $\times$-.. TSH

$-\mathrm{O}-$ : Control

\section{Effect of $p H$}

The iodinations of thyroglobulin were measured at various $\mathrm{pH}$ values in the presence or absence of TSH. The $\mathrm{pH}$ of the reaction medium was adjusted with phosphate buffers of various pH's (final concentration: $0.01 M$ ). The change in $\mathrm{pH}$ during the incubation was not discerned.

As shown in Figure 3, the rate of iodination in the presence of TSH was found to be higher than that in the absence of $\mathrm{TSH}$, over the whole range of $\mathrm{pH}$ 

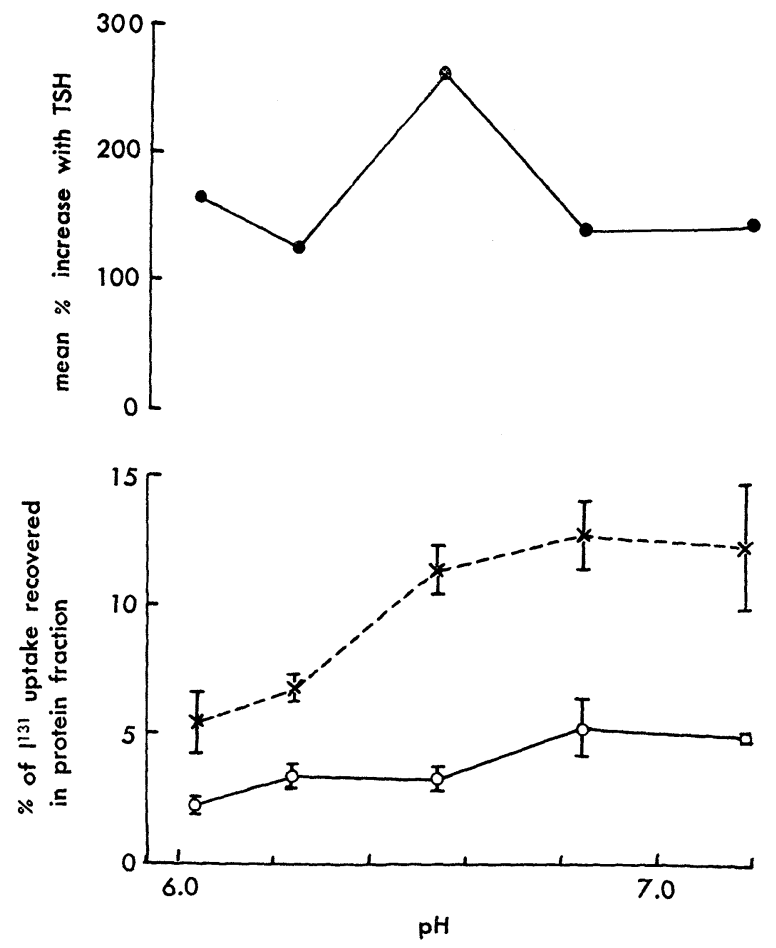

Fig. 3. Effect of $\mathrm{pH}$ upon the $1^{131}$-incorporation into protein fraction in thyroid slices $\ldots . . . \times \ldots . .+$ TSH

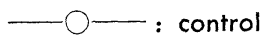

tested. A maximum stimulation was observed at $\mathrm{pH} 6.5$ although the extent of the iodination increased gradually with the increase in $\mathrm{pH}$ up to 6.8. It seems interesting that the $\mathrm{pH}$ of the intrafollicular colloid has been reported to be about 6.5 (De Robertis, 1941). However, definite conclusion on the optimal pH has not been obtained as it is impossible to control the $\mathrm{pH}$ of the site where iodination occurs.

\section{DISGUSSION}

The most important feature of the present assay is the simplicity of the reaction upon which it depends. Although thyroid slices preserve almost all phases of intrathyroidal iodine metabolism found in vivo, the stimulous effect of TSH observed in the present method is limited to the effect on the process of conversion of intrathyroidal iodide to thyroglobulin-bound iodine (Kondo, 196la and b); the stimulation seems to be independent of other processes such as collection of iodide, hydrolysis of thyroglobulin and secretion of thyroid hormone, if thyroid 
slices are incubated for a short period (15 mins.) under the present condition. It is not clear at present whether the primary site of action of TSH is really on the iodination of thyroglobulin, however, the importance of this reaction is also suggested from the observation that TSH enhances the cell-free iodination of thyroglobulin catalized by the thyroidal particulate fraction (Kondo, 1961c; Kondo and $\mathrm{Ui}, 1961$ ) or by the solubilized, partially purified enzyme preparation (Hosoya et al., 1962a and b).

The simplicity of the reaction utilized makes the present method especially useful for the study of the nature of TSH. The stimulating effect of TSH has been known in various aspects of intrathyroidal metabolism, which include several processes of iodine metabolism (Sonenberg, 1958; Pitt-Rivers and Tata, 1959), phospholipid synthesis (Freinkel, 1957) and glucose oxidation (Field et al., 1960 and 1961). It has not been fully decided whether all of these many effects on the thyroid are biological properties of a single hormone or they are the result of the existence of several different hormones. In order to settle the problem, it seems necessary to isolate highly purified, homogeneous preparation (s) with TSH activity. For this purpose assay procedures based on direct and primary response are required. Although ideal assay method has not been devised yet, the present assay might be of value because of the basic nature of the reaction utilized.

Generally speaking, in vitro assay has various advantages over in vivo method. The dilution of the hormone with blood flow and the modification of the hormone by organs other than the target organ can be eliminated in the former method. Technical simplicity is also one of the most important characteristics of in vitro method. In fact, various in vitro assay methods for TSH employing thyroid slices or fragments have been devised by a number of workers. Bakke and Lawrence (1956) studied the effect of TSH on collection and release of iodide and showed that the release of iodide might be a good index of TSH activity. Bottari (1957) and Bottari and Donovan (1958), employing tissue-cultured thyroid fragments, proposed the assay methods based on the uptake of $I^{131}$ and the depletion of previously stored labeled thyroid hormone, respectively. The sensitivity achieved by the latter method was the order of $0.1 \mathrm{I} . \mathrm{mU} . / 100 \mathrm{ml}$. In the methods devised by Hart et al. (1959), I ${ }^{131}$ uptake was measured by employing minced thyroid tissue obtained from several glands to reduce tissue variability, and 1 to $2 \mathrm{I}$. mU. of TSH could be detected. However, as incubation is continued more than $1 \mathrm{hr}$. in these methods, the observed responses would be influenced, more or less, by the several phases of iodine metabolism and by the susceptibility of slices to incubation.

Other in vitro assay methods, based on the enhanced incorporation of $\mathrm{P}^{32}$ in phospholipid fraction (Florsheim, 1957) and the stimulation of hexose monophosphate pathway (Dumont, 1961), have been suggested, but the relationship between these responses and those concerning iodine metabolism is not clear at present. Of interest is the method proposed by Bakke et al. (1957) in which the weight gain of incubated bovine thyroid slices was used as an index of response. These authors considered that this phenomenon was due to the stimulation of the hydrolysis of thyroglobulin within the thyroid follicle, but the view still waits confirmation. 
As an assay procedure, the present method is less sensitive than other methods recently proposed as method with high sensitivity, such as in vivo method of McKenzie (1958) (minimum detectable dose: 0.025 I. mU.) and in vitro method of Bottari and Donovan (1958) (useful range: $0.001 \sim 10 \mathrm{I} . \mathrm{mU}$. ). The present method shares the similar sensitivity to the in vitro methods based on the total uptake of $\mathrm{I}^{131}$ ion (Hart et al., 1959), the $\mathrm{P}^{32}$ incorporation (Florsheim, 1957) and glucose oxidation (Dumont, 1961). The reason for this insensitivity is not clear, but the short period of incubation might be partly responsible. At any rate preliminary condensation of TSH activity would be necessary before the determination of the activity in blood or urine is undertaken by the present method.

The advantage of this method with regard to technical convenience might be emphasized. As hog thyroid is obtainable from the slaughter-house at any time, the method offers considerable advantage especially to laboratories where need for assay arises only occasionally. Furthermore, it requires only 2 or 3 working hours for the preparation, incubation, and homogenization of slices, and, moreover the counting time of radioactivity on the paper strips in the following day is required. The facts that this method is economical and reliable also makes it attractive.

\section{SUMMARY}

A new assay method for thyrotropic hormone (TSH) based on the in vitro iodination of thyroglobulin, is presented. After incubation of hog thyroid slices for 15 mins. in a modified Krebs-Ringer phosphate buffer containing $0.05 \mu \mathrm{gI} / \mathrm{m} l$ of iodide labeled with $\mathrm{I}^{131}$ and TSH, the radio-activity in the protein fraction of slices was measured and utilized as an index of TSH activity. The usable range of this assay was $1 \mathrm{I} . \mathrm{mU} . / \mathrm{m} l$ to $30 \mathrm{I} . \mathrm{mU} . / \mathrm{m} l$ of $\mathrm{TSH}$ and the index of precision varied from 0.15 to 0.30 . Effects of temperature, $\mathrm{pH}$ and constituents of the medium upon the response were studied.

\section{REFERENCES}

Bakke, J.L. and N. Lawrence (1956). Endocrinology 58, 531.

Bakke, J.L., M.L. Heideman, Jr., N.L. Lawrence and G. Wiberg (1957). Ibid. 61, 683.

Bottari, P.M. (1957). Ciba Foundation Colloquia in Endocrinology 11, 52.

Bottari, P.M. and B.T. Donovan (1958). J. Physiol. (London) 140, 36.

Ciereszko, L.S. (1945). J. Biol. Chem. 160, 585.

Crigler, Jr. in Hormones in Human Plasma. Ed. by H.N. Antoniades, Little, Brown and Company, Massachusetts, p. 201 (1960).

De Robertis, E. (1941). Anat. Rec. 80, 219.

Dumont, J.E. (1961). Biochim. et Biophys. Acta 46, 195.

Field, J.B., I. Pastan, P. Johnson and B. Herring (1960). J. Biol. Chem. 235, 1863.

Field, J.B., I. Pastan, B. Herring and P. Johnson (1961). Biochim. et Biophys. Acta 50, 513.

Florsheim, W.H., M. Moskowitz, J.R. Schwartz, and M.E. Morton (1957). Endocrinology 60, 683. 
Freinkel, N. (1957). Ibid. 61, 448.

Hart, K.T., D. Druet and R.E. Mack (1959). Ibid. 64, 857.

Hosoya, T., Y. Kondo and N. Ui (1962a). Koso Kagaku Symposium 17, 46. (In Japanese)

Hosoya, T., Y. Kondo and N. Ui (1962b). J. Biochem. 52, 180.

Kondo, Y. (1961 a). Ibid. 50, 135.

Kondo, Y. (1961 b). Ibid. 50, 145.

Kondo, Y. (1961 c). Ibid. 50, 220.

Kondo, Y. and N. Ui (1961). Biochim. et Biophys. Acta 48, 415.

McKenzie, J.M. (1958). Endocrinology 63, 372.

McKenzie, J.M. (1960). Physiol. Rev. 40, 398.

Pitt-Rivers, R. and J.R. Tata. The Thyroid Hormones, Pergamon Press, London (1959).

Sonenberg, M. in Vitamins and Hormones. Ed. by R.S. Harris and K.V. Thimann, 16, Acad. Press Inc., N.Y., p. 205 (1958).

Turner, C.W. in Methods in Hormone Research. Ed. by R.I. Dorfman, Academic Press, N.Y. Vol. 2, p. 617 (1962). 